\title{
THE DIRECTION OF RESEARCH ESTABLISHMENTS
}

T HE scale, complexity and cost of scientific research are mounting rapidly. Laboratories are growing not only in number but also in size. To meet these ever-growing needs without waste of money or that vastly more precious commudity, scientific brain-power, a high order of organization and management is required. This is a comparatively new problem of administration-research has developed into a large-scale industry only in the past few decades-and there are almost no precedents in any field of human endeavour for showing the largescale organization of mental and imaginative creativeness as a team effort.

The direction of research establishments was the subject of an international symposium organized by, and held at, the National Physical Laboratory during September 26-28. Delegates from seventeen countries attended. They were mainly directors of large laboratories-government, industry and public corporations-with a small representation of universities. Attendance was severely limited to 150 . Papers were circulated before the conference, so that most of the conference time could be devoted to discussion.

The general plan of the symposium was that the first day should be devoted to choice of project, general problems of organization and control of research, and the personal and social factors affecting creativity in scientists. The second day provided three parallel sessions on general organization, staff and communication. The third day started with reports from, and joint discussion on, the previous day's sessions, followed by consideration of the assessment of the work of a research laboratory and a general summing up.

The proceedings were opened by Dr. G. B. B. M. Sutherland, who had just previously taken up his appointment as director of the National Physical Laboratory. The first session was then devoted to the strategy of research and the choice and termination of research projects. Prof. J. D. Bernal introduced a thought-provoking paper on "Fundamental and Applied Aspects of Research Problems". In this he emphasized that finding the problem is much more difficult than finding the solution. It is not the problem but the particular need or difficulty that stands out. It is necessary, therefore, before research is started, to reduce the immediately perceivable gap between what is known and what is required to something which can be measured scientifically. He described the working of various types of research laboratories and suggested that one of the most important aspects of the integration of research is that subsidiary problems should be referred to appropriate organizations such as research associations or national laboratories.

In dealing with invention, Prof. Bernal pointed out that its history shows that actual success depends not only on originality and imagination but also on knowing what to invent, that is, on a knowledge of requirements and of market possibilities and costs and prices. The frequent practice of firms in not allowing employees to profit directly from their invention was described as being the "best way of killing the goose that lays the golden egg'. Prof.
Bernal also thought that scientists tend to work too long on lines of traditional, set problems, whereas major advances have occurred when this rule is broken. $\mathrm{He}$ advocated a closer liaison between industrial and university research workers as providing two-way benefits.

The other paper in this session was by Dr. Willis Jackson, on "The Research Project-Its Choice and Termination". In this, comparisons and contrasts were drawn between the factors governing the initiation and termination of research in universities and in industry, although the outlook, approach and method of the true research worker were stated to be the same whatever his setting.

Dr. Willis Jackson gave various examples of work originating in individual inspiration which had exten. sive technological consequences not originally envisaged. He pointed out that the industrial research laboratory is fortunate in having ready access to the wider environment of a range of design and manufacturing activities as an outlet for its personnel. For this and other reasons he regarded it as essential for all industrial research recruits to spend a training period in carefully chosen departments of the main factory.

The first part of the second session was devoted to consideration of creativity. "Creativity and the Scientist" was introduced by Prof. Morris Stein, of the University of Chicagn, and "Personality and Social Fictors related to Creativity", by Prof. D. J. van Lennep, of the State University, Utrecht.

Prof. Stein surveyed the work of his team on the sociological and psychological factors related to creativity in industrial research chemists. The object of this work is the understanding of the processes involved in creativity so as to facilitate the selection of creative scientists and the administration of creative research. He stated that creativity is a process of hypothesis formation, hypothesis testing and communication of results, and that scientists can be creative in either or all of these fields. He stressed that there are differences between scientists working in different fields and in different environments, and advised employers to have a clear picture of the kind of man they want before starting to look for creativity.

Prof. van Lennep made a preliminary division of research workers under three categories: need for achievement, problem-solving ability and creativity; and he pointed out that a large research laboratory must have staff of each type. For physicists and chemists he postulated that creative workers are less dependent with respect to their environment; are less rigid and dogmatic and have a characteristic time perspective.

The final paper in this session was given by Mr. D. R. Willson, technical secretary of the Atomic Energy Research Establishment, Harwell, on "Budge.s and Administrative Controls". He discussed the needs for budgets and controls in research and development establishments, and how those which are essential can best be applied.

The general organization session started with discussions of a paper by Mr. E. S. Hiscocks, secretary of the National Physical Laboratory, on "Some 
Factors affecting Laboratory Administration". In this paper Mr. Hiscocks dealt first with the changed requirements caused by the transition of research from a craft to a large-scale industry. The effects of size on the organization were then examined and the great need for devolution stressed. The division of work in large laboratories was next considered, as were also the effects on their staffing and organization of large-scale, expensive equipment.

The next paper, on "Science and the Workshop", by Dr. R. Vieweg, president of the PhysikalischT'echnische Bundesanstalt, was presented by Dr. A. Scheibe, his vice-president. This discussed the place of workshops in laboratories and the types of shops and their organization to meet the requirements of modern research. This raised the controversial question of the degree of centralization of services required to produce optimum results.

The afternoon of this group session was devoted to laboratory buildings. Dr. F. M. Lea, director of the Building Research Station (Department of Scientific and Industrial Research), outlined the requirements and Mr. H. A. Snow, superintending architect, Ministry of Works, gave the architect's answer to these demands.

Punch remarked, more than twenty years ago, that the greatest of all the research problems is the people who do the research, and this was shown to be still the case by the discussions of the staff group. Dr. W. S. Bristowe, head of the Central Staff Department, Imperial Chemical Industries, Ltd., and Dr. F. T. Rosser, director of administration, National Research Council of Canada, presented papers on selection and personal assessment of staff. Dr. Rosser's account of what he described as "fantastic" methods used by employers in Canada to obtain scientists caused considerable comment in the daily press. Prof. H. A. Shepard, of the Massachusetts Institute of Technology, next discussed "Superiors and Subordinates in Research", and described the new orientations that have emerged from the work of sociologists in this field over the past twenty-five years. Prof. Shepard has himself made a significant contribution to these studies. Sir Charles Harington, director of the National Institute for Medical Research, then introduced the subject of "Staff Groupings and the Flow of Authority". The last subject discussed in this session was "Incentives". This was introduced by Mr. Stanley Mayne, secretary of the Institution of Professional Civil Servants. It was a refreshing experience for the 'managers' to hear the views of the 'managed' on this very important subject.

The third group session-that on communications - dealt first with internal communications in a large research laboratory and was introduced by Dr. C. C. Williams, director and general manager of 'Shell' Research, Ltd. This was followed by a paper "Studies in the Use of Technical Information in the Smaller Industrial Establishments", by Mr. Louis Moss and Mr. L. T. Wilkins, of the Central Office of Information. This paper described a statistical survey recently made into the dissemination of technical information in industry; and preliminary results of an investigation of the electrical and electronics industry in Great. Britain were presented for discussion by Mr. Geoffrey Thomas in the unavoidable absence of Mr. Moss.

Dr. A. T. Green, director of the British Ceramic Research Association, presented a paper by himself and Dr. A. E. Dodd, information officer of the Association, on "Knowledge: Passing it on-Getting it used", and Mr. A. J. Garratt, liaison officer of the National Physical Laboratory, dealt with problems of "Extramural Communications".

Mr. M. W. Thistle, chief of the Public Relations Branch, National Research Council of Canada, presented, in his inimitable style, the last paper in this group, on "Some Fundamental Difficulties in Popularizing Science". He contended that although only perhaps 0.01 per cent of information of a highly sophisticated nature can in fact be communicated to an unsophisticated audience, the amount of information emanating from science is such that the quantity ultimately absorbed is still significant.

Dr. D. W. Hill, director of the Shirley Institute, Didsbury, was chairman of the session on general organization, Jir. J. Bronowski, director of the Coal Research Establishment of the National Coal Board, was chairman of that on staff and Dr. A. King, Department of Scientific and Industrial Research, of that on communication. These chairmen presented to the complete conference next morning admirably lucid and stimulating summaries of the previous day's discussions.

The final session considered a paper on the assessment of the work of a research laboratory by Mr. A. H. Wilson, managing director of research and development, Courtaulds Ltd., and chairman of the Industrial Research Committee, Federation of British Industries. Mr. Wilson pointed out that the standing of an academic laboratory depends largely upon subjective judgments-the resthetic appeal of its results to the general body of academic scientists-whereas in the industrial world a laboratory is of no importance unless it exerts a positive influence on its industry, and this, ideally, is capable of measurement. On the subject of stopping research, Mr. Wilson advocated the early and continuous assessment of the whole project and its consequences-a process in which the research worker must take part and the consequences of which he should, therefore, accept. Discussion on this paper and on the conference in general was opened by Dr. A. V. Astin, director of the National Bureau of Standards, Washington.

A summing up of the conference was then given by Dr. H. W. Melville, secretary of the Department of Scientific and Industrial Research, who was chairman of this session.

It is impossible in an article of this length to summarize the many points of view put forward; but it became evident that many of the major problems of large-scale research are fundamentally the same whatever the country and whether the research is on behalf of government or industry. It was also surprising that the solutions evolved by apparently widely differing organizations bear close resemblances. This applies particularly to general organization of research services, and to the broad problems of the selection and personal assessment of staff. However, one of the major difficulties of the government research institution-what to do with the research scientist who has become less productive-is not shared to anything like the same extent by industry, where young men from the research department are continually transferred to other branches of the industry, such as technical sales, production, control, etc. The problems of internal communication are broadly similar whatever the type of industry and naturally increase with the size of the institution; but here again industry is not faced with many of the problems of external communication that are 
major concerns of government research for the civilian economy.

Although most of the participants in the symposium and many of the contributions came from those actually engaged in directing or administering large research establishments, considerable interest was shown in the 'research into research' papers, such as thos s from the psychologists, sociologists, statisticians and the trade union side. It is now clear to many research directors that, to borrow a phrase from Dr. Ellis Johnson, we should have more "operations research looking at research operations".

A surprise to the organizers of this symposium was the large number of people from many parts of the world who wished to attend, and it has become clear that discussion of problems such as those dealt with, and of the many more which time did not permit to be raised, must continue. The form which this follow-up and possible extension should take is now under consideration.

All papers presented at the symposium and summaries of the discussions will be published as soon as possible by H.M. Stationery Office, London.

E. S. HIscocks

\section{INTERNATIONAL SOCIETY OF BIOCLIMATOLOGY AND BIOMETEOROLOGY}

$\mathrm{T}$ HE first business and scientific meeting of the International Society of Bioclimatology and Biometeorology was held at Unesco House, Paris, during August 29-31. Approximately sixty members, representing sixteen nations, were present. The major items covered included the drawing up of a set of statutes; the election of an executive board and a governing council; the introduction to member's, through a series of area reports, of the various aspects of bioclimatological research in progress in different parts of the world; and the presentation of a small number of scientific papers.

Bioclimatology is not a new science, nor is it yet a unified one. The scope of the subject was brought out at the Paris meoting, and it speaks well of the new Society that its prime purpose should be to "unite ... all Bioclimatologists working in the fields of Medical, General Botanical, Agricultural, Forest, General Zoological, Veterinarian, Entomological and Cosmic Bioclimatology and other future branches of Bioclimatology,.... to facilitato the development of Bioclimatology". To achieve these ends it proposes to organize symposia, create a clearing house for publications, inaugurate a journal, institute subcommittees in specialized fields and, so far as possible, obtain funds for the fostering of research. The administration of the society is under the rgis of an executive board of seven members, assisted by a governing council of twenty-five. The following were elected to the executive board : President, Dr. F. Sargent (United States); Vice-Presidents, Prof. H. Berg (Germany), Dr. H. Boyko (Israel) and Prof. L. Emberger (France); Secretary-Treasurer, Dr. S. W. Tromp (Netherlands); and Advisory Members, Mr. W. E. Arnould-Taylor (Great Britain) and Dr. W. G. Wellington (Canada).

A total of seven area reports briefly described the work of individual bioclimatologists in North America, Western Europe, Africa, South-East Asia and Israel. Such a review provided an excellent, up-to-date account of research in progress. In addition, the width and variety of interests within the subject were made apparent through these reports, as can be seen from the inclusion of such topics as : asthma and hay-fever studies in relation to pollen, fungi and meteorological conditions of the atmosphere; the influence of climate on the behaviour and survival of forest insects ; the use of weather data in connexion with irrigation ; and a study of problems of clothing and resistance to extreme climates arising from pilgrimages by sea and land to Mecca.

Four sub-committees were instituted, the function of which is to collate and disseminate information on the respective specialized fields of ionic research in bioclimatology, allergy, ecological climatology and bioclimatological instruments. A proposed fifth subconmittee on nautical bioclimatology was referred to the executive board for further consideration.

It was proposed to hold a second meeting of the Society in Vienna in 1957, although a subsequent annual periodicity is not necessarily to be inferred. However, the Paris meeting showed many potential attenders to have been pre-occupied with earlier commitments, and lacunæ in some area reports suggest that scientists in certain areas and disciplines may not have fully realized the extensive nature of the Society's intentions. For these reasons and others, an early re-assembly appeared desirable.

The Society largely owes its inception to the initiative of Dr. S. W. Tromp, who got into touch with bioclimatologists in different parts of the world during the previous twelve months and also played a major part in the organization of the Paris meeting. His acceptance of the secretaryship, which he will conduct from 54 Hofbrouckerlaan Oegstgeest, Leyden, is a fortunate event for the Society.

M. J. Delany

F. L. WATERHOUSE

\section{YEAST IN INDUSTRY}

$\mathrm{U}$ NDER the joint sponsorship of the Dublin and District Section, the Microbiology Group and the Food Group of the Society of Chemical Industry, a symposium on "Recent Studies in Yeast and their Significance in Industry" was held in Dublin during September 17-19. The sessions were held in the Rupert Guinness Hall by kind invitation of Arthur Guinness Son and Co. (Dublin), Ltd., on behalf of whom Sir Richard Levinge welcomed the $125 \mathrm{mem}$. bers of the symposium; some seventy-five members attended from overseas. The basis of the symposium was provided by thirteen papers, the reading of which was followed by lively discussions in which many members participated. The chair was occupied in succession by Mr. H. J. Bunker, Prof. T. Dillon, Dr. A. K. Mills, Dr. A. J. Amos and Dr. I. A. Allen.

The first paper, by Dr. A. A. Eddy (Brewing Industry Research Foundation), dealt with "Some Chemical Aspects of Yeast Growth". First, Dr. Eddy described the use of media containing L-lysine as sole major source of nitrogen for the isolation of wild yeasts and the estimation of the extent to which they contaminate brewery pitching yeasts. He then discussed three commercially important aspects of the behaviour of yeasts, namely, head retention, flocculence and finability, which are associated with the surface structure of yeast. In particular, he 